\title{
KEADAAN MIKROBIOTA SALURAN CERNA PADA ANAK SEKOLAH DASAR YANG MENGALAMI STUNTING DI LOMBOK BARAT
}

\author{
(Condition of gut microbiota among stunted school children in West Lombok)
}

\author{
Siti Helmyati ${ }^{1 *}$, Endri Yuliati ${ }^{1}$, Setyo Utami Wisnusanti ${ }^{2}$, Risnhukathulistiwi Maghribi ${ }^{2}$, \\ Mohammad Juffrie ${ }^{3}$ \\ ${ }^{1}$ Program Studi Gizi Kesehatan, Fakultas Kedokteran, Universitas Gadjah Mada, Yogyakarta 55281 \\ ${ }^{2}$ Minat Gizi Kesehatan, Program Studi Ilmu Kesehatan Masyarakat, Fakultas Kedokteran, Universitas \\ Gadjah Mada, Yogyakarta 55281 \\ ${ }^{3}$ Bagian Kesehatan Anak, RSUP Dr. Sardjito, Yogyakarta 55284
}

\begin{abstract}
The purpose of this study was to compare the population of gut microbiota between the normal height and stunted in primary school children in West Lombok. The study design was observational study with comparative design. The study involved 115 primary school students with age 9-12 years old by simple random sampling. The research data included the measurement of height for age and gut microbiota analysis of faecal samples. Based on the results of t-test, the number of bacteria Lactobacillus in stunting group $(6.96 \pm 0.94 \log C F U / g)$ were significantly $(p<0.05)$ lower than normal group $(7,38 \pm 0,98$ $\log C F U / g)$. The population of Bifidobacteria, Enterobacter, and E. coli were not different between

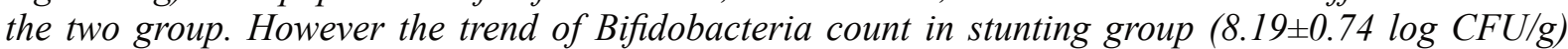
was lower than normal group $(8.22 \pm 0.79 \mathrm{log} C F U / \mathrm{g})$ while the number of Enterobacter and E. coli in stunting group (7.82 \pm 0.68 and $7.03 \pm 0.97 \log C F U / g)$ were higher than the normal group $(7.71 \pm 0.81$ and $6.96 \pm 1.22 \log C F U / g)$.
\end{abstract}

Keywords: gut microbiota, school children, stunting

\begin{abstract}
ABSTRAK
Penelitian ini bertujuan untuk membandingkan populasi mikrobiota saluran cerna antara kelompok anak yang memiliki tinggi badan normal dan anak pendek (stunting) di Sekolah Dasar di Kabupaten Lombok Barat. Desain penelitian yang digunakan adalah penelitian observasional dengan desain comparative. Penelitian melibatkan 115 siswa sekolah dasar dengan usia 9-12 tahun yang dipilih secara simple random sampling. Data penelitian meliputi pengukuran tinggi badan menurut umur dan analisa mikrobiota usus dari contoh feses. Berdasarkan hasil uji t-test, jumlah bakteri Lactobacillus kelompok stunting lebih rendah $(6,96 \pm 0,94 \log$ CFU/g) secara signifikan $(p<0,05)$ dibandingkan kelompok normal $(7,38 \pm 0,98$ $\log$ CFU/g). Jumlah bakteri Bifidobacteria, Enterobacter, dan E. coli tidak berbeda signifikan antara kedua kelompok. Namun kecenderungannya, Bifidobacteria kelompok stunting lebih rendah $(8,19 \pm 0,74$ $\log \mathrm{CFU} / \mathrm{g})$ dibanding kelompok normal $(8,22 \pm 0,79 \log \mathrm{CFU} / \mathrm{g})$ sedangkan jumlah bakteri Enterobacter dan E. coli pada kelompok stunting lebih tinggi $(7,82 \pm 0,68$ dan 7,03 $\pm 0,97 \log \mathrm{CFU} / \mathrm{g})$ dibanding kelompok normal $(7,71 \pm 0,81$ dan $6,96 \pm 1,22 \log \mathrm{CFU} / \mathrm{g})$.
\end{abstract}

Kata kunci: anak sekolah dasar, mikrobiota saluran cerna, stunting

\section{PENDAHULUAN}

Stunting atau pendek merupakan kondisi status gizi berdasarkan indeks tinggi badan menurut umur dengan nilai $z$-score $<-2$ standar deviasi dibandingkan dengan populasi standar (Direktorat Bina Gizi 2011). Stunting merupakan salah satu masalah gizi di Indonesia. Prevalensi stunting di Indonesia masih dikategorikan tinggi. Prevalensi stunting secara nasional sebe-

\footnotetext{
"Korespondensi: Telp: +6274547755, Surel: siti_helmyati@yahoo.com
} 
sar 37,2\%. Salah satu provinsi dengan angka stunting yang tinggi adalah Nusa Tenggara Barat. Nusa Tenggara Barat merupakan provinsi urutan ketiga dengan prevalensi stunting tertinggi di Indonesia. Prevalensi stunting di provinsi tersebut menurut Riset Kesehatan Dasar (Riskesdas) tahun 2013 lebih dari 45,3\%. Besar prevalensi lebih dari $40 \%$ tergolong kategori masalah serius menurut WHO (Balitbangkes 2013).

Stunting merupakan masalah gizi yang cukup serius karena merupakan penyakit gizi kronis dan memiliki dampak yang negatif. Dampak dari stunting terutama pada anak sekolah adalah memiliki prestasi belajar yang kurang (Picauly \& Toy 2013). Hal ini dapat menurunkan produktivitas kerja di masa mendatang. Stunting dapat disebabkan oleh banyak faktor. Berdasarkan penelitian, faktor yang menentukan kejadian stunting adalah pendapatan keluarga, pengetahuan gizi ibu, pola asuh ibu, infeksi penyakit, imunisasi, asupan gizi (Picauly \& Toy 2013). Faktor risiko stunting pada anak sekolah adalah asupan zat gizi yang kurang, kejadian diare dan penyakit infeksi seperti batuk dan flu (Mwaniki \& Makokhax 2013). Menurut analisis yang dilakukan Cahyono di Kabupaten Kupang, sanitasi lingkungan dan kejadian sakit seperti ISPA dan diare menjadi faktor risiko dari stunting (Cahyono et al. 2016).

Anak yang tinggal di kondisi dengan sanitasi yang buruk akan menyebabkan masalah penyakit dan infeksi di saluran cerna atau yang dinamakan environmental enteric dysfunction (Owino et al. 2016). Salah satu penyakit yang timbul akibat sanitasi yang buruk adalah diare. Diare memiliki peranan dalam kejadian stunting. Anak yang mengalami stunting mempunyai episode kejadian diare yang sering (Checkley et al. 2008; Pop et al. 2014). Diare berkaitan dengan kondisi bakteri patogen yang tinggi di dalam saluran cerna. Komposisi mikrobiota saluran cerna pada saat diare berubah menjadi lebih tinggi komposisi bakteri patogennya dibandingkan probiotik di dalam saluran cerna (Dinh et al. 2016; Gough et al. 2015)

Diketahui bahwa setiap individu memiliki komposisi mikrobiota saluran cerna yang berbeda-beda. Faktor usia dan daerah tempat tinggal juga dapat menentukan komposisi mikrobiota saluran cerna ini. Penelitian menunjukkan bahwa anak-anak di Bangladesh mempunyai jenis dan jumlah mikrobiota yang berbeda dengan anakanak di Amerika Serikat. Namun anak di Amerika Serikat mempunyai komposisi mikrobiota yang relatif sama dengan orang dewasa di Bangladesh (Lin et al. 2013). Penelitian lain menunjukkan bahwa komposisi mikrobiota saluran cerna pada anak sekolah di Kulon Progo tidak berbeda signifikan dengan di Nusa Tenggara Barat (Helmyati et al. 2015). Populasi mikrobiota dapat dipengaruhi oleh genetik, dan dapat berubah akibat gaya hidup, penyakit infeksi, penggunaan antibiotik, asupan makan dan faktor lain (Tyakht 2013). Sedangkan faktor risiko stunting antara lain karena asupan zat gizi yang kurang dan penyakit infeksi (Mwaniki \& Makokha 2013). Asupan zat gizi anak stunting yang kurang bisa karena tidak terpenuhinya jumlah atau jenis bahan makanan yang dibutuhkan dan juga lamanya infeksi. Keadaan ini dapat menimbulkan perubahan komposisi mikrobiota saluran pencernaan antara bakteri patogen dan komensal (Owino et al. 2016). Oleh karenanya perlu diteliti lebih mendalam mengenai komposisi mikrobiota saluran cerna pada anak sekolah yang stunting maupun yang tidak stunting terutama di daerah dengan prevalensi stunting tinggi. Tujuan dari penelitian ini adalah untuk membandingkan populasi mikrobiota saluran cerna anak sekolah dasar yang mempunyai tinggi normal dengan anak stunting.

\section{METODE}

\section{Desain, tempat, dan waktu}

Desain penelitian ini adalah penelitian observasional dengan desain comparative. Penelitian dilakukan di tiga sekolah dasar di Kabupaten Lombok Barat. Penentuan lokasi penelitian menggunakan randomisasi sekolah yang ada di Kabupaten tersebut. Penelitian dilakukan selama bulan Februari-April 2015.

\section{Jumlah dan cara pengambilan subjek}

Kriteria inklusi subjek penelitian ini adalah anak sekolah dasar yang berusia 9-12 tahun, mengalami stunting dengan $z$-score indeks $\mathrm{TB} / \mathrm{U}<-2,00 \mathrm{SD}$, bersedia ikut dalam penelitian dan diijinkan oleh orang tua/wali untuk mengikuti penelitian. Kriteria eksklusinya adalah mengonsumsi antibiotik dalam tiga bulan terakhir dan sedang dalam masa pengobatan medis. Jumlah subjek dihitung dengan rumus Lemeshow untuk penelitian cross sectional, proporsi anak stunting di Provinsi Nusa Tenggara Barat pada tahun 2014 sebesar 36,43\% (Dinkes Prov NTB 2015), power yang digunakan dalam penelitian ini sebesar 90\%, tingkat kemaknaan 95\% $(\alpha=5 \%)$ dan diperoleh total besar sampel minimal sebanyak 89 subjek.

Subjek penelitian dipilih dari sampel penelitian induk, dimana perhitungan perhitungan 
sampel pada penelitian induk dilakukan berdasarkan Sastroasmoro dan Ismael (2002) untuk penelitian eksperimental dengan power yang digunakan dalam penelitian ini sebesar $90 \%$, tingkat kemaknaan $95 \%(\alpha=5 \%)$, perkiraan selisih rerata variabel yang diteliti yaitu kadar hemoglobin sebesar 8,6 g/dl dan standar deviasi sebesar 9,6 $\mathrm{g} / \mathrm{dl}$ sehingga didapatkan besar sampel minimal 104 untuk 4 perlakuan. Pengambilan subjek didahului dengan skrining. Teknik pemilihan subjek dengan purposive sampling kemudian subjek dan orang tua subjek diminta kesediaannya untuk menjadi subjek.

Subjek dibagi menjadi dua yaitu kelompok stunting sebanyak 71 anak dan kelompok normal sebanyak 44 anak. Keterbatasan dalam penelitian ini adalah proporsi yang tidak seimbang antara subjek pada kelompok stunting dengan kelompok normal.

\section{Tahapan penelitian}

Pengumpulan data subjek. Data yang dikumpulkan berupa data karakteristik yang meliputi usia, jenis kelamin, pendidikan dan pekerjaan orang tua/wali, data tinggi badan anak, dan data uji mikrobiota saluran cerna. Data karakteristik anak diperoleh dengan wawancara oleh enumerator dan ditulis di dalam kuesioner karakteristik subjek. Tinggi badan anak diukur oleh tenaga terlatih menggunakan microtoise dengan tingkat ketelitian $0,1 \mathrm{~cm}$. Tinggi badan subjek dinyatakan dalam satuan $\mathrm{cm}$ dan dihitung $z$-score indeks tinggi badan menurut umur menggunakan aplikasi WHO Anthro Plus. Setelah mendapatkan $z$-score indeks tinggi badan menurut umur, subjek digolongkan menjadi kelompok normal dan pendek/stunting. Subjek dimasukkan dalam kelompok tinggi badan normal apabila $z$-score indeks $\mathrm{TB} / \mathrm{U} \geq-2,00 \mathrm{SD}$. Jika nilai $z$-score indeks $\mathrm{TB} / \mathrm{U}<-2,00 \mathrm{SD}$ maka dimasukkan dalam kelompok stunting/pendek.

Prosedur pengumpulan feses dan pengujian mikrobiota. Pengumpulan contoh feses dibantu oleh tenaga enumerator terlatih. Subjek dan orangtua subjek diberi instruksi untuk mengontak enumerator jika subjek akan buang air besar (BAB). Subjek yang didatangi adalah subjek yang mengontak enumerator dan BAB sekitar pukul 07.00-15.00 WIT. Contoh feses subjek dimasukkan ke dalam tabung steril yang telah disediakan dan tidak boleh bercampur dengan air seni, air kloset maupun kotoran lainnya. Contoh feses yang dimasukkan sekitar 2-5 g. Tabung steril tersebut diberi label berupa kode, nama responden, tanggal, dan jam pengambilan. Tabung steril berisi contoh feses dibawa dalam coolbox yang berisi ice gel dan langsung dianalisa di laboratorium.

Mikrobiota yang diuji adalah jumlah bakteri Lactobacillus, Bifidobacteria, E. Coli dan Enterobacter dalam saluran cerna subjek yang dinyatakan dalam satuan Colony Forming Unit (CFU)/gram feses contoh. Keempat genus bakteri ini dipilih untuk menggambarkan komposisi antara parameter bakteri probiotik yaitu Lactobacillus dan Bifidobacteria serta bakteri patogen yaitu E. Coli dan Enterobacter (Jandhyala et al. 2015).

Mikrobiota saluran cerna diperoleh dari uji laboratorium di Laboratorium Imunobiologi, Fakultas MIPA, Universitas Mataram dengan contoh feses. Jumlah sel bakteri Lactobacilli, Bifidobacteria, Enterobacteriaceae dan E. coli di dalam feses dihitung dengan metode plating pada media selektif agar (teknik kultur). Jumlah sel bakteri dinyatakan dalam $\log \mathrm{CFU} / \mathrm{g}$.

Analisa mikrobiota menggunakan metode pour plate (Soestbergen \& Lee 1969). Feses subjek jika berbentuk cair diambil $1 \mathrm{ml}$, jika berbentuk padatan maka diambil $1 \mathrm{~g}$. Feses yang telah disiapkan diencerkan menggunakan $\mathrm{NaCl} 0,85 \%$ steril. Setelah homogen, contoh feses dimasukkan kedalam seri pengenceran dengan konsentrasi $10^{-1}$ hingga $10^{-7}$. Setiap seri pengenceran, dimasukkan $1 \mathrm{ml}$ feses kedalam cawan petri. Media agar dituangkan sesuai bakteri yang akan diuji sebanyak 15-20 g, kemudian media diratakan dan ditunggu hingga memadat. Setelah itu, diinkubasi pada suhu $37^{\circ} \mathrm{C}$ selama 24 jam (untuk E. coli dan Enterobacter) atau 48 jam (untuk Lactobacillus dan Bifidobacteria). Setelah selesai inkubasi, koloni yang tumbuh pada media dihitung menggunakan quebec colony counter.

\section{Bahan dan alat}

Alat yang digunakan untuk menggali data karakteristik subjek penelitian adalah kuesioner. Alat yang digunakan untuk mengukur tinggi badan adalah microtoise. Pemeriksaan mikrobiota usus memerlukan alat antara lain; tabung feses steril, coolbox, ice gel, cawan petri, laminary flow, incubator $37^{\circ} \mathrm{C}$, waterbath, quebec colony counter, autoclave, coolroom, vortex, timbangan, falcon, micropippete, blue tip dan alat gelas.

Bahan-bahan yang diperlukan untuk menganalisa mikrobiota usus antara lain: contoh feses, aquades, $\mathrm{NaCl}$ 0,85\% steril, MRS agar (Merck), Bifidobacterium Selective Agar (Fluka), Mac Conkey agar (Oxoid), Chromocult ${ }^{\circledR}$ TBX (Tryptone Bile X-Glucuronide) agar (Fluka). 
Helmyati dkk.

\section{Pengolahan dan analisis data}

Data tinggi badan diolah menjadi $z$-score indeks tinggi badan menurut umur menggunakan aplikasi WHO Anthro Plus kemudian dikategorikan menjadi stunting dan normal. Data mikrobiota disajikan dalam mean \pm SD dalam satuan log $\mathrm{CFU} / \mathrm{g}$. Data dianalisa melalui uji independent $t$-test menggunakan software statistika STATA versi 13 .

\section{HASIL DAN PEMBAHASAN}

Tabel 1 menunjukkan bahwa karakteristik subjek penelitian antara dua kelompok tidak berbeda signifikan pada $p>0,05$. Jenis kelamin, pendidikan dan pekerjaan orangtua antara kelompok normal dengan stunting.

Tabel 2 menunjukkan jumlah bakteri $L a c$ tobacillus pada anak yang stunting $(6,96 \pm 0,94$ $\log \mathrm{CFU} / \mathrm{g})$ lebih rendah signifikan $(\mathrm{p}<0,05)$ dibandingkan kelompok anak normal $(7,38 \pm 0,98$ $\log \mathrm{CFU} / \mathrm{g})$. Hasil ini didukung oleh penelitian Helmyati et al. (2015), bahwa kadar Lactobacillus pada 27 anak yang sehat di NTB sebanyak $7,19 \pm 0,83 \log \mathrm{CFU} / \mathrm{g}$. Menurut Zimmerman et al. (2010), total populasi Lactobacillus yang normal pada anak sekitar 6-8 log CFU/g. Hal ini juga sejalan dengan penelitian Ghosh et al. (2014). Penelitian tersebut dilakukan pada anak di India yang dikelompokkan menjadi tiga yaitu anak sehat, anak malnutrisi pada borderline dan anak dengan malnutrisi parah.

Anak yang sehat memiliki komposisi mikrobiota saluran cerna yakni mikrobiota patogen yang lebih sedikit daripada anak malnutrisi. Berdasarkan hasil penelitian, perbedaan populasi pada bakteri Lactobacillus memang signifikan secara statistik tetapi kedua kelompok masih dalam rentang normal. Kondisi mikrobiota pada subjek penelitian ini belum memberikan hubungan klinis terhadap kejadian stunting, sehingga perlu didukung de-ngan faktor yang lain, seperti tinggi badan orang tua, personal hygiene, infeksi, tingkat ekonomi dan asupan gizi yang kurang (Mwaniki \& Makokha 2013).

Penelitian lain yang dilakukan pada anak di India bagian selatan menunjukkan bahwa anak sehat memiliki komposisi jumlah bakteri Bifidobacterium longum dan Lactobacillus mucosae yang lebih banyak dibanding anak stunting (Dinh et al. 2016). Hasil tersebut belum dapat dibuktikan dalam penelitian ini, walaupun ada kecenderungan jumlah Bifidobacteria pada anak yang sehat juga lebih tinggi $(8,22 \pm 0,79 \log \mathrm{CFU} / \mathrm{g})$ dibanding anak yang stunting $(8,19 \pm 0,74 \log \mathrm{CFU} / \mathrm{g})$, namun hasilnya tidak signifikan $(p>0,05)$. Jum-
Tabel 1. Karakteristik subjek penelitian

\begin{tabular}{|c|c|c|c|}
\hline Karakteristik & $\begin{array}{c}\text { Kelompok } \\
\text { Normal } \\
\text { n (\%) }\end{array}$ & $\begin{array}{c}\text { Kelompok } \\
\text { Stunting } \\
\mathrm{n}(\%)\end{array}$ & $\mathrm{p}$ \\
\hline \multicolumn{4}{|l|}{ Jenis kelamin } \\
\hline Laki-laki & $22(50 \%)$ & $31(44 \%)$ & 0,508 \\
\hline Perempuan & $22(50 \%)$ & $40(56 \%)$ & \\
\hline \multicolumn{4}{|c|}{ Pendidikan Ayah } \\
\hline Tamat PT & $1(2 \%)$ & $3(4 \%)$ & \\
\hline Tamat SMA & $15(34 \%)$ & $12(17 \%)$ & \\
\hline Tamat SMP & $9(20 \%)$ & $20(28 \%)$ & 0,320 \\
\hline Tamat SD & $13(30 \%)$ & $24(34 \%)$ & \\
\hline $\begin{array}{l}\text { Tidak } \\
\text { sekolah }\end{array}$ & $6(14 \%)$ & $12(17 \%)$ & \\
\hline \multicolumn{4}{|l|}{ Pendidikan Ibu } \\
\hline Tamat PT & $0(0 \%)$ & $2(3 \%)$ & \\
\hline Tamat SMA & $7(16 \%)$ & $12(17 \%)$ & \\
\hline Tamat SMP & $10(23 \%)$ & $16(23 \%)$ & 0,843 \\
\hline Tamat SD & $20(45 \%)$ & $29(40 \%)$ & \\
\hline $\begin{array}{l}\text { Tidak } \\
\text { sekolah }\end{array}$ & $7(16 \%)$ & $12(17 \%)$ & \\
\hline \multicolumn{4}{|l|}{ Pekerjaan Ayah } \\
\hline Buruh & $26(59 \%)$ & $54(77 \%)$ & \\
\hline Honorer & $1(2 \%)$ & $1(1 \%)$ & \\
\hline Petani & $5(12 \%)$ & $5(7 \%)$ & 0,446 \\
\hline PNS & $1(2 \%)$ & $1(1 \%)$ & \\
\hline Wiraswasta & $11(25 \%)$ & $10(14 \%)$ & \\
\hline \multicolumn{4}{|l|}{ Pekerjaan Ibu } \\
\hline IRT & $24(55 \%)$ & $36(51 \%)$ & \\
\hline Buruh & $18(41 \%)$ & $30(42 \%)$ & \\
\hline Petani & $1(2 \%)$ & $2(3 \%)$ & 0,942 \\
\hline Swasta & $0(0 \%)$ & $1(1 \%)$ & \\
\hline PNS & $1(2 \%)$ & $2(3 \%)$ & \\
\hline
\end{tabular}

Tabel 2. Rata-rata komposisi mikrobiota saluran cerna antara dua kelompok

\begin{tabular}{lccc}
\hline \multicolumn{1}{c}{ Mikrobiota } & $\begin{array}{c}\text { Kelompok } \\
\text { normal }\end{array}$ & $\begin{array}{c}\text { Kelompok } \\
\text { stunting }\end{array}$ & $\mathrm{p}$ \\
\hline $\begin{array}{l}\text { Lactobacillus } \\
(\log \text { CFU/g) }\end{array}$ & $7,38 \pm 0,98$ & $6,96 \pm 0,94$ & $0,0239 *$ \\
$\begin{array}{l}\text { Bifidobacteria } \\
(\log \text { CFU/g) }\end{array}$ & $8,22 \pm 0,79$ & $8,19 \pm 0,74$ & 0,8805 \\
$\begin{array}{l}\text { Enterobacter } \\
(\log \text { CFU/g) }\end{array}$ & $7,71 \pm 0,81$ & $7,82 \pm 0,68$ & 0,4458 \\
$\begin{array}{l}\text { E.coli } \\
(\log \text { CFU/g) }\end{array}$ & $6,96 \pm 1,22$ & $7,03 \pm 0,97$ & 0,7000 \\
*signifikan & & &
\end{tabular}

J. Gizi Pangan, Volume 12, Nomor 1, Maret 2017 
lah Bifidobacteria normal yaitu mencapai 9-10 $\log$ CFU/g (Ishibashia \& Shimamura 1993). Hasil penelitian menunjukkan populasi Bifidobacteria pada kedua kelompok subjek di bawah angka normal. Namun rendahnya populasi Bifidobacteria ini belum dapat dijelaskan karena penelitian ini memiliki keterbatasan yaitu tidak dikumpulkannya data pendukung seperti gambaran kejadian infeksi pada kedua kelompok.

Tabel 2 menunjukkan bahwa tidak ada perbedaan signifikan $(\mathrm{p}>0,05)$ pada jumlah bakteri E.coli dan Enterobacter antara kelompok anak yang stunting maupun normal. Populasi E.coli kedua kelompok pada penelitian ini masuk dalam range normal karena total populasi normal E.coli pada anak sekitar $10^{6}-10^{8}$ bakteri atau 6-8 log CFU/g (Zimmermann et al. 2010). Namun, kecenderungan jumlah koloni patogen lebih banyak pada anak yang stunting $(7,82 \pm 0,68$ dan 7,03 $\pm 0,97 \log \mathrm{CFU} / \mathrm{g}$ ) dibandingkan anak normal $(7,71 \pm 0,81$ dan $6,96 \pm 1,22 \log \mathrm{CFU} / \mathrm{g})$. Berdasarkan penelitian yang dilakukan Ghosh et al. (2014) bahwa mikrobiota saluran cerna pada anak berbeda-beda komposisinya tergantung status gizi. Semakin buruk status gizi seorang anak, maka komposisi mikrobiota yang ada di dalam saluran cerna lebih banyak mikrobiota patogen (Ghosh et al. 2014). Penelitian lain juga menunjukkan bahwa anak stunting, mikrobiota saluran cernanya kaya akan bakteri inflammogenic seperti genus Desulfovibrio dan ordo Campylobacterales (Dinh et al. 2016).

Pertumbuhan berlebih bakteri pada usus halus berhubungan dengan sanitasi yang buruk dan stunting (Gough et al. 2015; Owino et al. 2016). Hubungan tersebut dapat dijelaskan karena adanya mekanisme diare. Pertumbuhan bakteri patogen yang berlebihan pada saluran cerna yang diakibatkan karena infeksi dan imun yang rendah akan menyebabkan probiotik yang ada di saluran cerna menurun. Komposisi bakteri patogen yang banyak menyebabkan inflamasi dan malabsorbsi zat gizi sehingga menyebabkan stunting (Donowitz et al. 2016). Penyakit infeksi dan asupan gizi yang buruk mampu menyebabkan environmental enteric dysfunction. Keadaan ini menyebabkan inflamasi pada saluran cerna, ketidakseimbangan populasi mikrobiota dalam saluran cerna dan malabsorbsi zat gizi. Kondisi tersebut akan menyebabkan pertumbuhan linear terganggu (Gough et al. 2015; Owino et al. 2016). Keterbatasan penelitian ini adalah tidak adanya data kejadian diare pada subjek.

\section{KESIMPULAN}

Jumlah bakteri Lactobacillus pada subjek stunting dan subjek status gizi normal masih dalam batas populasi seimbang, walaupun pada kelompok stunting lebih rendah secara signifikan dibandingkan kelompok normal $(\mathrm{p}<0,05)$. Komposisi bakteri Bifidobacteria, Enterobacter, dan $E$. coli tidak berbeda signifikan antara kedua kelompok. Namun kecenderungannya, Bifidobacteria kelompok stunting lebih rendah dibanding kelompok normal sedangkan jumlah bakteri Enterobacter, dan E. coli pada kelompok stunting lebih tinggi dibanding kelompok normal.

\section{UCAPAN TERIMA KASIH}

Terima kasih diucapkan kepada Nestle Foundation atas pendanaan penelitian, Dinas Kesehatan Nusa Tenggara Barat dan subjek penelitian atas kerjasama dalam penelitian ini.

\section{DAFTAR PUSTAKA}

[Balitbangkes] Badan Penelitian dan Pengembangan Kesehatan. 2013. Riset Kesehatan Dasar 2013. Jakarta: Balitbangkes.

Cahyono F, Manongga SP, \& Picauly I. 2016. Faktor penentu stunting anak balita pada berbagai zona ekosistem di Kabupaten Kupang. J Gizi Pangan, 11(1):9-18.

Checkley W, Buckley G, Gilman RH, Assis AMO, Guerrant RL, Valentiner-branth P, Lanata CF, Black RE, Morris SS. 2008. Multi-country analysis of the effects of diarrhoea on childhood stunting. International Journal of Epidemiology 37:816830. http://doi.org/10.1093/ije/dyn099.

Dinh DM, Ramadass B, Kattula D, Sarkar R, Naumova EN, Kang G, Ward HD. 2016. Longitudinal analysis of the intestinal microbiota in persistently stunted young children in South India. Plos One 11(5):1-17.http:// doi.org/10.1371/journal.pone.0155405.

Dinas Kesehatan Provinsi NTB. 2015. Profil Kesehatan Provinsi NTB Tahun 2015. Mataram: Dinkes Prov Mataram.

Direktorat Bina Gizi. 2011. Keputusan Menteri Kesehatan RI: Standar Antropometri Penilaian Status Gizi Anak. Jakarta.

Donowitz JR, Haque R, Kirkpatrick BD, Alam M, Lu M, Kabir M, Kakon H. 2016. Small intestine bacterial overgrowth and environmental enteropathy in Bangla- 
Helmyati dkk.

deshi children. mBio 7(1):1-7. http://doi. org/10.1128/mBio.02102-15.Editor.

Ghosh TS, Gupta SS, Bhattacharya T, Yadav D, Barik A, Chowdhury A, Nair GB. 2014. Gut microbiomes of Indian children of varying nutritional status. Plos One 9(4): 113.

Gough EK, Stephens DA, Moodie EEM, Prendergast AJ, Stoltzfus RJ, Humphrey JH, \& Manges AR. 2015. Linear growth faltering in infants is associated with Acidaminococcus sp . and community- level changes in the gut microbiota. Microbiome 3(24): 1-10.doi:10.1186/s40168-015-0089-2.

Helmyati S, Juffrie M, Rahayu ES, \& Kandarina I. 2015. A comparative study of gut morobiota profiles of children living ini Kulon Progo and West Lombok. Pakistan Journal of Nutrition 14(11):762-764.

Ishibashi N, Ashimamura. 1993. Bifidobacteria : Research and development in Japan. Food Tech 47:129-134.

Jandhyala SM, Talukdar R, Subramanyam C, Vuyyuru H, Sasikala M, \& Reddy DN. 2015. Role of the normal gut microbiota. World J Gastroenterol 21(29):8787-8803.

Lin A, Bik EM, Costello EK, Dethlefsen L, Haque R, Relman DA, \& Singh U. 2013. Distinct distal gut microbiome diversity and composition in healthy children from Bangladesh and the United States. Plos One 8(1). http://doi.org/10.1371/journal. pone. 0053838 .

Mwaniki dan Makokha. 2013. Nutrition status and associated factors among children in public primary schools in Dagoretti, Nairobi, Kenya. African Health Sciences 13(1):39-46.
Oktarina Z, Sudiarti T. 2013. Faktor risiko stunting pada balita (24-59 bulan) di Sumatera. J Gizi Pangan 8(3):175-180.

Owino V, Ahmed T, Freemark M, \& Kelly P. 2016. Environmental enteric dysfunction and growth failure / stunting in global child health. Pediatrics 138(6). http://doi. org/10.1542/peds.2016-0641.

Picauly I, \& Toy SM. (2013). Analisis determinan dan pengaruh stunting terhadap prestasi belajar anak sekolah di Kupang dan Sumba Timur, NTT. J Gizi Pangan 8(1):55-62.

Pop M, Walker AW, Paulson J, Lindsay B, Antonio M, Hossain MA, Stine OC. 2014. Diarrhea in young children from lowincome countries leads to large-scale alterations in intestinal microbiota composition. Genome Biol 15(6):1-12. http://doi. org/10.1186/gb-2014-15-6-r76.

Sastroasmoro S, Ismael. 2002. Dasar-dasar Penelitian Klinis. Jakarta: Sagung Seto.

Soestbergen AAV, Lee CH. 1969. Pour Plates Or Streak Plates? Applied Microbiology 18(6):1092-1093.

Tyakht AV, Kostrykova ES, Popenko AS, Belenikin MS, Pavlenko AV, Larin AK. 2013. Human gut microbiota community structures in urban and rural population in Russia. Nat Commun 4:2469.

Zimmermann MB, Chassard C, Rohner F, Goran KN, Nindjin C, Dostal A. (2010). The Effects of Iron Fortification on the Gut Microbiota in African Children : a Randomized Controlled trial in Cote d'Ivoire. Am J Clin Nutr 92(6):1406-1415. 